\title{
INFLUENCE OF OZONE ON GERMINATION AND GERMINATING ENERGY OF WINTER WHEAT SEEDS
}

\author{
Valentina Avdeeva, Elena Zorina, Julia Bezgina, Olga Kolosova \\ Stavropol State Agrarian University, Russia \\ avdeeva_vn@mail.ru,zeb26@mail.ru,juliya.bezgina@mail.ru,kolosova.07@mail.ru
}

\begin{abstract}
Obtaining high quality crop yields is one of the most important economic problems of Russia. The yield of agricultural crops depends on the quality of the sowing material and its preparation for sowing. Currently modern technologies of processing seed based are used on applying various types of physical factors. Positive experiences on the use of the magnetic field, infrared and laser radiations, the currents of ultra-high frequencies to increase germination and seed growth are known. Unlike traditional methods of presowing treatment of seeds with chemicals, electrical methods are environmentally clear and do not have negative side effects on plants. One of the most promising methodsfrom an environmental point of view is ozonation. Scientists have determined that the ozonized air contributes to the improvement of sowing qualities of seeds. However, optimization of ozone treatment with the aim of increasing energy of growth and germination as the main indicators of sowing qualities requires improvement. In Educational and scientific testing laboratory of the Stavropol State Agrarian University for several years the research to examine the impact of environmentally safe ways on increasing the sowing qualities of seeds of grain crops was conducted. In particular, there was a twofactor experiment conducted on the influence of ozone on the improvement of the sowing qualities of seeds of winter wheat. Seed treatment was carried out on an industrial ozonator "Ozone-60P". Determination of ozone concentration was performed using a gas analyzer "Cyclone-5.41". It is proved that pre-treatment with ozone leads to increased germinating energy and seed germination. The article presents the optimal parameters of seed treatment of winter wheat with ozone to promote their sowing qualities.
\end{abstract}

Keywords: seeds of wheat, ozonation, ozone dose, germination, germinating energy.

\section{Introduction}

One of the most important tasks of agriculture is obtaining high quality yields of agricultural crops. The yield of agricultural crops largely depends on the quality of the seed material and its preparation for sowing. At present, the scientific and practical interest is in the search for effective, environmentally safe methods of influencing the seeds of agricultural crops in order to increase their sowing qualities.

A special place is occupied by electrophysical factors, which, unlike traditional methods of presowing seed treatment with chemicals, are environmentally friendly and do not have a negative side effect on seeds and further on plants. There are positive experiments on the use of a magnetic field, infrared and laser radiation, microwave currents to improve the germination and energy of seed germination. One of the most promising methods for treating seeds from an ecological point of view is ozonation. Ozone technologies can be conditionally divided into two major directions. The first direction is aimed at stimulating the vital activity of living organisms, for which it is necessary to apply ozone concentrations at the maximum permissible concentration (MPC) level. The second direction is connected with the suppression of the vital activity of harmful organisms or with the elimination of harmful contaminants from the surrounding atmosphere. Ozone concentrations in this case are much higher than the MAC level. Scientists have established that ozonized air contributes to the improvement of the seed quality of seeds. However, the optimization of ozonation regimes with the aim of increasing the germination and germinating energy as the main indicators of crop quality requires improvement.

The use of ozonized air in agriculture was carried out by scientists such as Aboltins A., Palabinskis J., Kince T., Galoburda R., Klava D., Blija A., Kerch G., Borodin IF, Starodubtseva G. P., Oskin S.V., Shevchenko A.A., Ksyonz N.V. In particular, Starodubtseva G.P., Rubtsova E.I., Shevchenko A.A. processed beet, buckwheat, soybean, spring and winter wheat seeds in order to improve the germination and germinating energy.

\section{Materials and methods}

Having studied the experience of scientists in the field of ozone technologies, at the Stavropol State Agrarian University, for 5 years we conducted exploratory experiments on the effect of ozone - 
air flow on the germination and energy of seed germination of winter wheat. Ozone-air stream 52 of samples of winter wheat seeds from different agroclimatic zones of the Stavropol Territory with different ozone concentrations were treated with ozone-air flow. For purity of the experiments, statistical analysis of the data was carried out by the method of variance analysis for two-factor experiments on a PC (BA Dospekhov, 1985).

The use of ozone for presowing seed treatment was carried out by Borodin IF, Starodubtseva G.P., Oskin S.V., Shevchenko A.A., Ksyonz N.V. and other scientists. Having studied the experience of scientists in the field of ozone technologies, at the Stavropol State Agrarian University, for 5 years we conducted exploratory experiments on the effect of ozone - air flow on the germination and energy of seed germination of winter wheat. Based on the results of the research, a two-factor experiment was conducted to determine the effect of ozone on the sowing quality of winter wheat seeds. It is difficult to determine the limits of the positive effect of ozone on the germinating energy and the germination capacity of the grain, since the effect of three factors was noted: the ozone concentration, the time of seed treatment by the ozone-air flow, and the exposure of the sample after treatment. Therefore, in order to develop a unified approach to assessing the effect of ozone on seeds, we introduced the notion of "treatment dose". The treatment dose is calculated with the formula

$$
D=c \cdot t,
$$

where $D$ - treatment dose, $\mathrm{g} \cdot \mathrm{s} \cdot \mathrm{m}^{-3}$

$\varepsilon$ - ozone concentration, $\mathrm{g} \cdot \mathrm{m}^{-3}$;

$t$ - seed treatment time (exposition), s.

Seeds of wheat for the research are delivered to the laboratory from different climatic zones of the Stavropol Territory. Seed treatment was carried out on an industrial ozonizer "Ozone-60P" with an ozone concentration of $0.035 \mathrm{~g} \cdot \mathrm{m}^{-3}$. The determination of the ozone concentration was carried out with the aid of the "Cyclone-5.41" gas analyzer. Seeds were laid on germination on potato-glucose agar in Petri dishes at a temperature of $25^{\circ} \mathrm{C}$ in a six fold repetition of 100 grains of the sample. The germinating energy was determined on day 3 after seed laying, germination was determined on day 7 of seed germination. The control over these parameters was also carried out, without treatment with ozone the energy of germination of wheat seeds was $67 \%$, germination - $73 \%$. Statistical processing of the experimental data was carried out by the method of variance analysis for a two-factor experiment on a PC (B.A.Dospekhov, 1985). Factor A - doses of seed treatment with ozone. Doses of treatment were selected taking into account the preliminary experiments conducted in the educational and scientific testing laboratory and amounted to $2,1,8,4,9,9,10,512,6,14,716,8,18,9,19,8 \mathrm{~g} \cdot \mathrm{s} \cdot \mathrm{m}^{-3}$. Factor B - the time of seed removal from ozone treatment before laying on germination $(0,7,14$ days).

\section{Results and discussion}

The results of the experiments on the effect of ozone on the germinating energy of winter wheat seeds of the varieties Victoria Odesskaya and Ermak are presented in Tables 1 and 2.

As it can be seen from Table 1, doses from 12.6 to $18.9 \mathrm{~g} \cdot \mathrm{s} \cdot \mathrm{m}^{-3}$ had a significant effect on the germinating energy of winter wheat seeds. A further increase in the treatment dose $\left(19.8 \mathrm{~g} \cdot \mathrm{s} \cdot \mathrm{m}^{-3}\right)$ was the beginning of a decrease in the germinating energy. The exposure time of the grain after treatment also affected the germinating energy. The germinating energy reached its maximum value, when the samples were exposed after 14 days treatment.

Analysis of Table 2 confirms the effect on the germinating energy of winter wheat seeds of an ozone dose from 12.6 to $18.9 \mathrm{~g} \cdot \mathrm{s} \cdot \mathrm{m}^{-3}$.

The results of the experiments on the effect of ozone on the germination of winter wheat seeds of the varieties Victoria Odesskaya and Ermak are presented in Tables 3 and 4.

The experiments have shown that the germination of winter wheat seeds also increases as the dose of ozone-air stream treatment increases. This indicator varies significantly, starting with an ozone dose of $9.9 \mathrm{~g} \cdot \mathrm{s} \cdot \mathrm{m}^{-3}$, the maximum germination value reached, when treating ozone with doses of $16.8 \mathrm{~g} \cdot \mathrm{s} \cdot \mathrm{m}^{-3}$ in the first sample, $\mathrm{g} \cdot \mathrm{s} \cdot \mathrm{m}^{-3}-14.7$ in the second sample. 
Influence of ozone on the energy of seed germination of wheat variety Victoria Odesskaya, \% (control - 67.0 \%)

\begin{tabular}{|c|c|c|c|c|}
\hline \multirow{2}{*}{ Ozone dose, $\mathbf{g} \cdot \mathbf{s} \cdot \mathbf{m}^{-\mathbf{3}}, \mathbf{x}$} & \multicolumn{3}{|c|}{ Exposition of grain, days, $\mathbf{y}$} & \multirow{2}{*}{ Average value } \\
\cline { 2 - 4 } & 0 & 7 & $\mathbf{2}$ & \\
\hline $\mathbf{2 . 1}$ & $\mathbf{7 0 . 3}$ & $\mathbf{7 0 . 5}$ & $\mathbf{7 1 . 0}$ & $\mathbf{7 0 . 6}$ \\
\hline 8.4 & 74.5 & 74.5 & 76.0 & 75.0 \\
\hline 9.9 & 80.0 & 80.0 & 82.0 & 80.7 \\
\hline 10.5 & 83.3 & 84.8 & 85.3 & 84.4 \\
\hline 12.6 & 85.0 & 88.0 & 88.0 & 87.0 \\
\hline 14.7 & 85.8 & 85.8 & 88.0 & 86.5 \\
\hline 16.8 & 88.5 & 89.0 & 92.0 & 89.8 \\
\hline 18.9 & 86.0 & 87.0 & 89.0 & 87.3 \\
\hline $\mathbf{1 9 . 8}$ & $\mathbf{7 0 . 8}$ & $\mathbf{7 0 . 0}$ & $\mathbf{6 9 . 5}$ & $\mathbf{7 0 . 1}$ \\
\hline Average value & 80.4 & 81.1 & 82.3 & \\
\hline \multicolumn{4}{|l}{$\mathbf{H C P}_{\mathbf{x v}, \mathbf{0 . 9 5}=\mathbf{2 . 4}}$} \\
\hline
\end{tabular}

Influence of ozone on the energy of seed germination

of wheat variety Ermak, \% (control - 69.0 \%)

\begin{tabular}{|c|c|c|c|c|}
\hline \multirow{2}{*}{ Ozone dose. $\mathbf{g} \cdot \mathbf{s} \cdot \mathbf{m}^{-\mathbf{3}} \mathbf{,} \mathbf{x}$} & \multicolumn{3}{|c|}{ Exposition of grain. days. $\mathbf{y}$} & \multirow{2}{*}{ Average value } \\
\cline { 2 - 4 } & 0 & 7 & 14 & \\
\hline $\mathbf{2 . 1}$ & $\mathbf{7 2 . 0}$ & $\mathbf{7 2 . 5}$ & $\mathbf{7 1 . 3}$ & $\mathbf{7 1 . 9}$ \\
\hline 8.4 & 82.0 & 81.0 & 84.0 & 82.3 \\
\hline 9.9 & 83.0 & 81.0 & 84.0 & 82.7 \\
\hline 10.5 & 83.0 & 81.0 & 84.0 & 82.7 \\
\hline 12.6 & 87.0 & 87.0 & 88.7 & 87.6 \\
\hline 14.7 & 87.0 & 87.0 & 90.0 & 88.0 \\
\hline 16.8 & 88.0 & 88.0 & 91.0 & 89.0 \\
\hline 18.9 & 88.0 & 88.0 & 91.0 & 89.0 \\
\hline $\mathbf{1 9 . 8}$ & $\mathbf{7 2 . 8}$ & $\mathbf{7 3 . 5}$ & $\mathbf{7 3 . 3}$ & $\mathbf{7 3 . 2}$ \\
\hline Average value & 82,5 & 82,1 & 84,1 & - \\
\hline \multicolumn{4}{|l|}{$\mathbf{H C P}_{\mathbf{x y} . \mathbf{0 . 9 5}=\mathbf{3 . 1}}$} \\
\hline
\end{tabular}

Influence of ozone on the germination capacity of wheat seeds of Victoria Odesskaya, \% (control - 73.0 \%)

\begin{tabular}{|c|c|c|c|c|}
\hline \multirow{2}{*}{ Ozone dose. $\mathrm{g} \cdot \mathrm{s} \cdot \mathrm{m}^{-3}, \mathrm{x}$} & \multicolumn{3}{|c|}{ Exposition of grain, days, $y$} & \multirow{2}{*}{ Average value } \\
\hline & 0 & 7 & 14 & \\
\hline 2.1 & 76.3 & 75.8 & 75.8 & 75.9 \\
\hline 8.4 & 80.3 & 80.5 & 81.0 & 80.6 \\
\hline 9.9 & 85.0 & 84.0 & 88.0 & 85.7 \\
\hline 10.5 & 84.0 & 85.0 & 88.0 & 85.7 \\
\hline 12.6 & 89.0 & 89.8 & 91.0 & 89.9 \\
\hline 14.7 & 91.0 & 91.0 & 95.0 & 92.3 \\
\hline 16.8 & 91.0 & 91.0 & 94.0 & 92.0 \\
\hline 18.9 & 88.0 & 89.0 & 89.0 & 88.7 \\
\hline 19.8 & 73.5 & 73.7 & 73.8 & 73.7 \\
\hline Average value & 84.2 & 84.4 & 86.1 & - \\
\hline \multicolumn{5}{|c|}{$\mathrm{HCP}_{\mathrm{xy} .0 .95}=2.8$} \\
\hline
\end{tabular}


Influence of ozone on the germination capacity

of wheat seeds of Ermak, \% (control - 75.0 \%)

\begin{tabular}{|c|c|c|c|c|}
\hline \multirow{2}{*}{ Ozone dose, $\mathrm{g} \cdot \mathrm{s} \cdot \mathrm{m}^{-3}, \mathrm{x}$} & \multicolumn{3}{|c|}{ Exposition of grain, days, $y$} & \multirow{2}{*}{ Average value } \\
\hline & 0 & 7 & 14 & \\
\hline 2.1 & $\mathbf{7 7 . 5}$ & 79.8 & 80.0 & 79.0 \\
\hline 8.4 & 82.0 & 83.0 & 84.0 & 83.0 \\
\hline 9.9 & 86.0 & 86.0 & 89.0 & 87.0 \\
\hline 10.5 & 86.0 & 86.0 & 88.0 & 86.7 \\
\hline 12.6 & 90.0 & 90.0 & 94.0 & 91.3 \\
\hline 14.7 & 92.0 & 91.0 & 94.5 & 92.5 \\
\hline 16.8 & 90.0 & 90.0 & 94.8 & 91.6 \\
\hline 18.9 & 90.0 & 90.0 & 93.0 & 91.0 \\
\hline 19.8 & 74.3 & 74.3 & 76.8 & 75.1 \\
\hline Average value & 85.3 & 85.6 & 88.2 & - \\
\hline \multicolumn{5}{|c|}{$\mathrm{HCP}_{\mathrm{xy} \cdot 0.95}=3.3$} \\
\hline
\end{tabular}

The germination of seeds of the Ermak variety increased by $19.5 \%$ compared to the control $(75.0 \%)$ and was $94.5 \%$ with the exposure of 14 days. A similar result was obtained in the study of seeds of winter wheat of Victoria Odesskaya variety. The control was $73.0 \%$, in the best case the germination rate increased by $22.0 \%$, with the ozone dose amounting to $14.7 \mathrm{~g} \cdot \mathrm{s} \cdot \mathrm{m}^{-3}$.

Similar results were obtained in the study of 46 samples of winter wheat seeds.

\section{Conclusions}

Thus, the results of the experiments performed treating winter wheat seeds with an ozone-air stream make it possible to assume that ozone improves the germination and germinating energy of the seeds. Optimal parameters for treating wheat seeds with ozone to stimulate the germination and energy of germination of seeds should be considered: doses of 14.0-17.0 g. $\mathrm{s} \cdot \mathrm{m}^{-3}$; recommended seed ripening from the time of ozone treatment to laying for germination for 14 days.

At present, the Stavropol State Agrarian University is developing a complex system for processing wheat seeds with physical factors in order to improve the quantitative and qualitative characteristics of cereals.

\section{References}

[1] Aboltins A., Palabinskis J., Lauva A. Grain active ventilation using ozonized air 2010. Acta Horticulturae.

[2] Avdeeva V.N. Application of ecological methods of suppression of pathogenic mycoflora of winter wheat grain during storage: diss. Cand.s.-. sciences. / V.N.Avdeeva. - Stavropol, 2009.

[3] Avdeeva V.N. Application of ecological methods of suppression of pathogenic mycoflora of winter wheat grain during storage: the author's abstract. diss.Cand.s.-. sciences. / V.N.Avdeeva. Stavropol, 2009, 24 p.

[4] Avdeeva V.N., BezginaYu.A., Volosova E.V. Modern technologies for improving the quality of seeds, Vestnik APK Stavropolya. 2016. No. 1 (21). pp. 116-118.

[5] Shevchenko A.A. Effect of ozone on cereals / A.A. Shevchenko, E.A. Saprunova, R.S. Shkhalakhov, Physico-technical problems of creating new technologies in the agro-industrial complex: Sat. sci.tr. SSAU. - Stavropol, 2003, pp. 645-646.

[6] Kince T., Galoburda R., Klava D., Blija A., Kerch G. Effect of processing on microbial safety, total phenolic content and radical scavenging activity of germinated hull-less barley flakes.Journal of Food, Agriculture and Environment, 2017.

[7] Starodubtseva G.P. Influence of presowing treatment by ozone-air flow on sowing quality of soybean seeds / G.P. Starodubtseva, V.I. Hainovsky, E.I. Rubtsova, Physico-technical problems of creating new technologies in the agro-industrial complex : Sat. sci.tr. on the basis of the IV Russian Scientific and Practical Conference / SSAU. - Stavropol, 2007, pp. 410-416. 